\title{
Oncology
}

Arasawa, S. 11

Arizumi, T. 4, 27, 47, 53

Chishina, H. 4, 27, 47

Hagiwara, S. 4, 27, 47, 53

Hamada, M. 33

Hatae, T. 42

Hayashi, Y. 42

Hiramatsu, Y. 60

Ida, H. 4, 47, 53

Imai, Y. 33

Imawsaki, N. 33

Imoto, S. 42, 60

Inokuma, T. 33

Inoue, T. 4, 47

Iwanishi, M. 4, 47

Izuta, M. 11

Kariyama, K. 19

Kim, K.I. 42, 60

Kim, S.K. 42, 60

Kim, S.R. 42, 60

Kishida, M. 19

Kitai, S. 4, 27, 47
Kitano, M. 4, 47

Kobayashi, M. 60

Kono, M. 4, 47

Kubo, A. 11

Kudo, M. 1, 4, 11, 19, 27, 33

Kudo, M. 42

Kudo, M. 47, 53, 60

Matsunaka, T. 11

Minami, T. 4, 27, 47, 53

Minami, Y. 4, 11, 27, 47

Minowa, K. 33

Mizuguchi, A. 60

Murakami, T. 27

Nishida, N. 4, 27, 47, 53

Nishimura, M. 19

Noda, T. 11

Nouso, K. 19

Ogawa, C. 11

Ohtani, A. 42, 60

Ohyama, A. 19

Oonishi, A. 19

Otono, Y. 60
Sakurai, T. 4, 47, 53

Sasaki, I. 33

Shibatoge, M. 11

Sugahara, M. 33

Sugimoto, K. 42, 60

Suginoshita, Y. 33

Takita, M. 4, 27, 47, 53

Tamaki, H. 11

Tamura, T. 60

Tei, H. 33

Tochio, H. 33

Tohyama, M. 42, 60

Tsurusaki, M. 27

Ueshima, K. 4, 27, 47, 53

Wakuta, A. 19

Yada, N. 4, 27, 47, 53

Yagyu, Y. 27

Yano, Y. 42

\section{Subject Index Vol. 89, Suppl. 2, 2015}

ART score 4

Asunaprevir 42

Balloon-occluded transcatheter arterial chemoembolization 27

BCLC stage B 47

BCLC-B 19

CD8-positive T cell 33

Chronic hepatitis B 60

Contrast-enhanced ultrasonography 33

Daclatasvir 42

Direct-acting antivirals 42

Entecavir 60
Hepatocellular carcinoma 4, 11, 27, 42, 47

Interferon-free treatment 42

Intermediate-stage hepatocellular carcinoma 19

Kinki criteria 47

Kupffer cell 33

Liver cancer 33

Net amount of effective shear wave velocity 53

Nucleos(t)ide analogues 60

Occurrence 42

Overall survival 4
Pegylated interferon- $\alpha 60$

Prevention 42

Programmed cell death-1 antibody 33

Radiofrequency ablation 19

Real-time virtual sonography 11

Recurrence 42

Reliability index 53

Shear wave elastography 53

_ _ imaging 53

- _ measurement 53

Sonazoid 33

SYNAPSE VINCENT 11

Tenofovir 60

Transarterial chemoembolization 4, 47 